\section{OPEN ACCESS}

Edited by:

Wulf Rössler,

Charité-Universitätsmedizin

Berlin, Germany

Reviewed by:

Nader Salari,

Kermanshah University of Medical

Sciences, Iran

Mahbobeh Faramarzi

Babol University of Medical

Sciences, Iran

*Correspondence:

Hamidreza Aghamohammadian

Sharbaf

aghamohammadian@um.ac.ir

Specialty section:

This article was submitted to

Public Mental Health,

a section of the journal

Frontiers in Psychiatry

Received: 10 December 2019

Accepted: 16 September 2020

Published: 05 November 2020

Citation:

Zarif Golbar Yazdi H, Aghamohammadian Sharbaf $\mathrm{H}$, Kareshki H and Amirian M (2020) Psychosocial Consequences of

Female Infertility in Iran: A Meta-Analysis.

Front. Psychiatry 11:518961. doi: 10.3389/fpsyt.2020.518961

\title{
Psychosocial Consequences of Female Infertility in Iran: A Meta-Analysis
}

\section{Haniye Zarif Golbar Yazdi ${ }^{1}$, Hamidreza Aghamohammadian Sharbaf ${ }^{1 *}$, Hossein Kareshki ${ }^{1}$ and Malihe Amirian ${ }^{2}$}

${ }^{1}$ Department of Psychology, Ferdowsi University of Mashhad, Mashhad, Iran, ${ }^{2}$ Department of Reproductive Medicine and Gynecology, Milad (Mashhad) Infertility Center, Mashhad, Iran

Background: Although not a life-threatening condition, infertility does influence various aspects of life. Based on a meta-analysis of the relevant literature, the aim of this study is to identify the psychosocial consequences of infertility in Iranian women.

Methods: Comprehensive Portal of Human Sciences, Magiran, Scientific Information Database, Noormags, MEDLIB, ScienceDirect, Google Scholar, Medline, and ProQuest were the databases searched from inception (1999) to 2018. To maximize the comprehensiveness of the search, the reference lists of all the relevant papers identified were manually examined. The evaluation of the content was based on PRISMA guidelines, and Comprehensive Meta-Analysis software was used for data analysis.

Results: Based on the analysis of 124 quantitative papers, the psychosocial consequences of infertility in women in Iran can be classified into 14 categories: psychological well-being (effect size $=3.10$ ), adaptation to infertility (effect size $=2.71$ ), quality of life (effect size $=1.83$ ), depression (effect size $=1.80$ ), anxiety (effect size $=1.72$ ), marital relationships (effect size $=1.37$ ), personality disorders (effect size $=1.37$ ), violence (effect size $=1.31$ ), social support (effect size $=0.90$ ), self-efficacy (effect size $=0.90$ ), coping strategies (effect size $=0.84$ ), irrational thoughts (effect size $=0.77$ ), somatization disorders (effect size $=0.65$ ), and sexual dysfunction (effect size $=0.55$ ).

Conclusion: Considering the wide-ranging psychosocial consequences of infertility in women, it is necessary for treatment to account for psychological factors.

Keywords: infertility, psychosocial consequences, Iran, review, meta-analysis

\section{INTRODUCTION}

Infertility is characterized by the failure to achieve a clinical pregnancy despite 12 months of regular and unprotected sexual intercourse (1). The global prevalence of infertility is $\sim 9-12.5 \%$ $(2,3)$. According to studies conducted in Iran, the total mean of infertility and the rate of primary infertility prevalence are $13.2 \%$ (4) and $17.3 \%$ (5), respectively; these figures are higher than the global average. Although not a life-threatening condition, infertility has intense psychosocial consequences. Infertility diagnosis and the subsequent treatment process usually impose excruciating stress on couples. Several studies have reported that couples with infertility 
are prone to experiencing depression (6), anxiety (7), sexual intercourse problems, marital problem $(8,9)$, decrease in selfconfidence (10), and low levels of psychological well-being (11, 12) and quality of life (13).

Although infertility has an emotional impact on both partners, studies have shown that it imposes greater pressure on women, as demonstrated by the fact that $50 \%$ of infertile women considered this the biggest problem in their lives (14). In a previous study, many women with infertility stated that they could not imagine a life without children, while this was not the case with men (15). Further, it is mainly women who are subjected to fertility treatments, which serves to increase their psychological burden.

The stress and anxiety in women with infertility arises from issues such as missing out on the experience of motherhood, negative self-concept, and inability to continue the family line. Moreover, societal pressures are responsible for the extensive psychological consequences in women with infertility (16). In many cultures, infertility is perceived as something to be ashamed of (17). Specifically, owing to cultural and social factors as well as religious beliefs, having children is much more crucial in Asian compared to Western countries (18). In many traditional cultures, the male partners of women who are unable to bear children often remarry. In Iran, infertility can be considered a legal basis of divorce; that is, it is permitted upon the request of either partner (19).

Since infertility is an unexpected stress in the lives of couples, they are usually not equipped with the necessary information and appropriate coping strategies. Therefore, it is of paramount importance that psychological factors be taken into account during the treatment of infertility. Accordingly, the aim of this meta-analysis of studies concerning the psychological consequences of infertility in women is to provide experts with the data required to design therapy programs to preclude and decrease the negative effects of infertility in women. In this regard, this study seeks to answer the following question: What does the literature reveal about the psychological consequences of infertility in Iranian women?

\section{MATERIALS AND METHODS}

This study was conducted according to PRISMA guidelines. To investigate the entirety of the body of published research concerning the psychological consequences of infertility in women in Iran, the databases searched included Comprehensive Portal of Human Sciences, Magiran, Scientific Information Database, Noormags, MEDLIB, ScienceDirect, Google Scholar, Medline, and ProQuest. To maximize the comprehensiveness of the search, the reference lists for all the relevant papers were manually examined.

\section{Search Strategy}

The search strategy was based on the PICOS model, as follows: $\mathrm{P}$-infertile Iranian women, I-psychological interventions or assessment were done about psychosocial consequences of female's infertility, $\mathrm{C}$-fertile Iranian people, $\mathrm{O}$-psychosocial consequences of infertility, S-randomized control trial studies, pretest and posttest, quasi-experimental, and descriptive studies.
To identify papers in the aforementioned electronic databases, the keywords used were "infertility," "women's infertility," "primary infertility," "secondary infertility," "quality of life," "wellbeing," "mood disorder," "anxiety disorder," "sexual dysfunction," "psychological distress," and combinations of these words.

\section{Inclusion and Exclusion Criteria}

For studies to be included in this meta-analysis, they had to meet certain inclusion and exclusion criteria. The inclusion criteria were studies that (19) were published from inception (1999) to 2018, (20) investigated the psychological consequences of infertility, (21) reported sufficient data to measure effect sizes, (22) were in the form of full papers, published either online or accessible in library archives, and (23) had Iranian authors, although the text could be in either Persian or English. The exclusion criteria were studies that (19) did not provide fulltext access, (20) did not report information necessary to measure effect sizes, and (21) were duplicate articles based on reviewing titles and abstracts.

\section{Statistical Analysis}

In this study, we employed Hedges' effect size to quantitatively evaluate the results. To elaborate, we first drew a funnel plot to identify publication bias. Following the sensitivity analysis and exclusion of studies with publication bias, we determined the effect size of every psychosocial consequence of infertility in women in Iran as well as the effect size using fixed and random models. Further, to investigate the heterogeneity of the effect sizes in the initial studies, that is, those that did not make it to the final analysis stage despite originally meeting certain criteria, we employed Cochran's Q and the chi-l index. Comprehensive MetaAnalysis software (CMA; Biostat, Inc.) was used for data analysis.

\section{RESULTS}

Out of the 474 papers initially identified in the electronic databases, 73 and 121 were excluded in the first stage owing to the incongruity of their topics and duplication. As a result, a total of 346 papers were selected for the next stage. In this stage, the authors investigated the texts of the papers. A total of 156 papers that had a low quality based on PRISMA principles were excluded from the list. At this point, 124 papers were selected for the metaanalytic process (Figure 1). Details on the studies are presented in Table 1.

A total of 292 effect sizes from the studies that initially entered the meta-analysis were measured. The reason for the number of effect sizes being greater than the number of included studies was the fact that every study contained numerous variables related to the psychosocial consequences of infertility. Since one of the main assumptions of our meta-analysis was the absence of publication bias, we first employed a graphic method (funnel plot) to identify publication bias and eliminate those studies.

By observing the funnel plot (Figure 2), it can be seen that the points are not distributed symmetrically around the plot, owing to the uncommon and deviated values of the effect sizes. Further elimination of three effect sizes led to a symmetrical shape in the funnel plot (Figure 2). Finally, from the 124 papers determined 


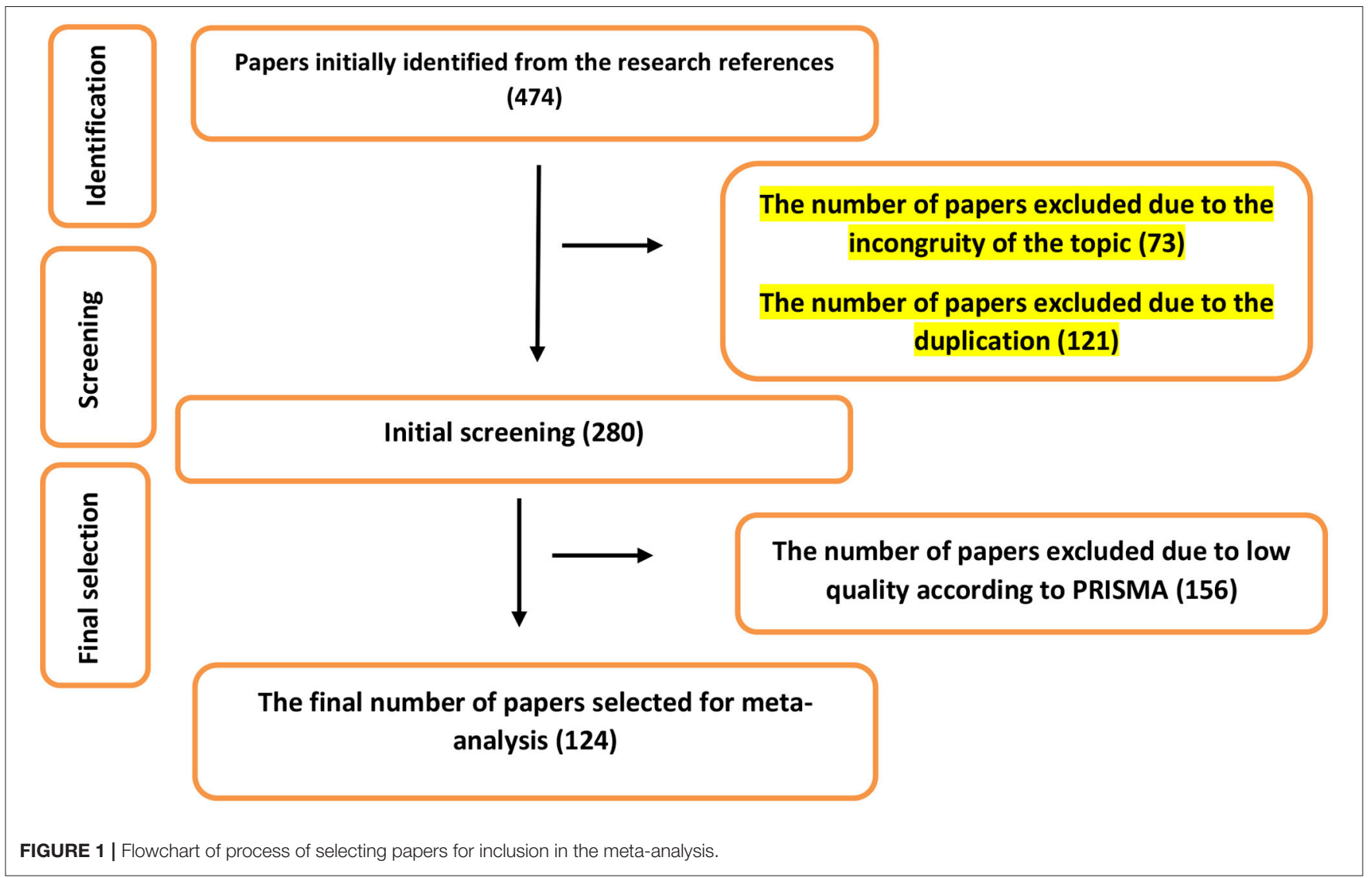

to be appropriate for meta-analysis, a total of 243 effect sizes regarding the psychosocial consequences of infertility in women were identified.

Table 2 presents the number of papers for each psychosocial consequence, and their mean effect sizes, according to Hedges' effect size index. Based on the results presented in Table 1, it is evident that the maximum effect size-3.10-relates to psychological well-being. Therefore, it can be deduced that the most significant psychosocial consequence of infertility among women is the psychological well-being variable and its related factors. In addition, the minimum Hedges' effect size-0.55relates to sexual dysfunction. Thus, sexual dysfunction is the least significant psychosocial consequence of infertility in women.

Table 3 illustrates the combined effect of the fixed and random models in Iranian studies on the psychosocial consequences of female infertility after sensitivity analysis. The means of the combined effect sizes for the psychosocial consequences of female infertility in fixed and random models were 0.58 and 1.03 , respectively, both of which were statistically significant $(P \leq 0.00)$.

To specify the final meta-analysis model, a set of heterogeneity tests had to be conducted to ensure the presence of moderating variables. To examine the heterogeneity of the effect sizes in the studies, the Egger's test, Cochran's Q and Chi-I indices were employed. Egger's regression intercept tests revealed no evidence of publication bias $(\rho=0.24)$. The value obtained for the $Q$ index (for 243 effect sizes) was 2,777.90, with a 242 degree of freedom, which was statistically significant $(P \leq 0.00)$ and indicated an actual difference between the effect sizes of the initial studies. Furthermore, the Chi-I results indicated that $91.28 \%$ of the variance present in the initial study results was real and could be obtained using moderating variables. Based on the criteria laid down by Bornstein, Hedges, Higgins, and Rothstein (142), a high heterogeneity is indicated in the initial studies. Based on the two heterogeneity indices, it was determined that the moderating variables played significant roles in the importance of the psychosocial consequences in women with infertility. Therefore, the random model was selected for meta-analysis, 1.03 was considered to be the combined effect size.

\section{DISCUSSION}

In this study, we performed a meta-analysis of Iranian studies on the psychological consequences of infertility in women. The aim was to synthesize the findings available in the literature, along with facilitating more precise future conclusions and presenting the possibility of devising plans to preclude, or at least decrease, such consequences.

As the results indicate, well-being is the psychological aspect most significantly impacted by infertility in women, with 19 significant effect sizes and a Hedges' effect size of 3.10. This is noteworthy, since existing studies have placed more emphasis on negative emotional factors than positive emotional factors. According to the definition provided by the World Health 
TABLE 1 | Summary of studies included in review.

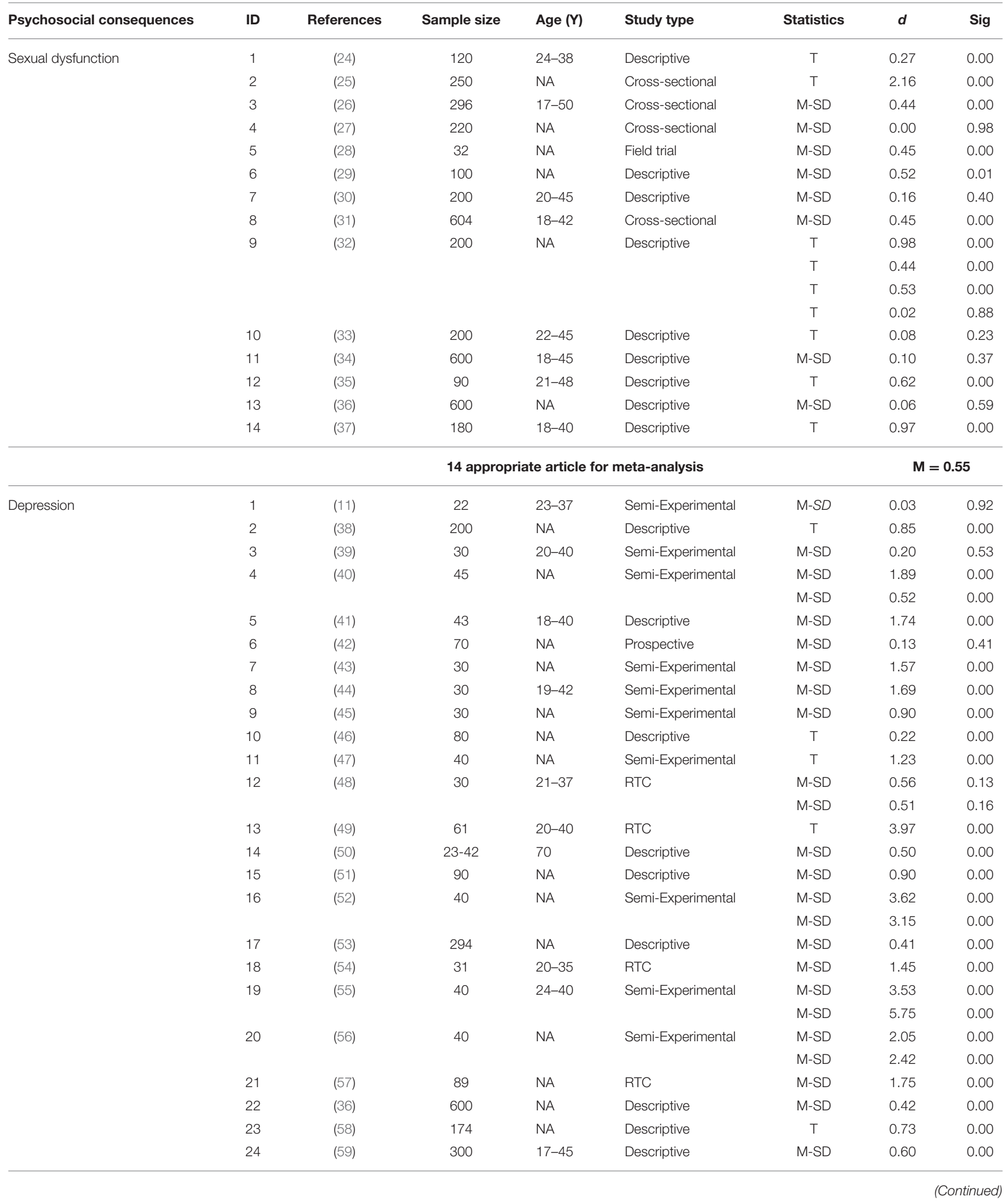


TABLE 1 | Continued

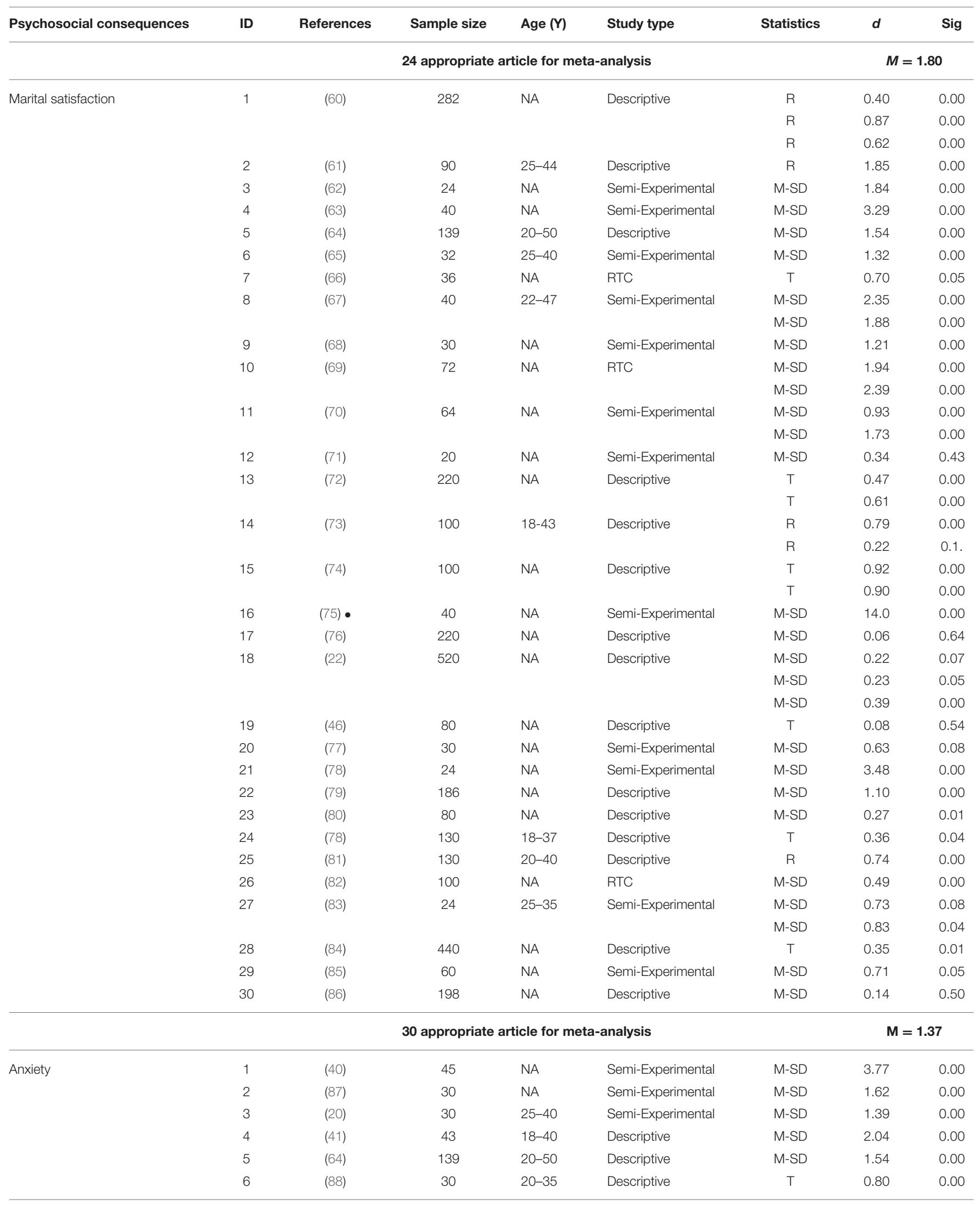


TABLE 1 | Continued

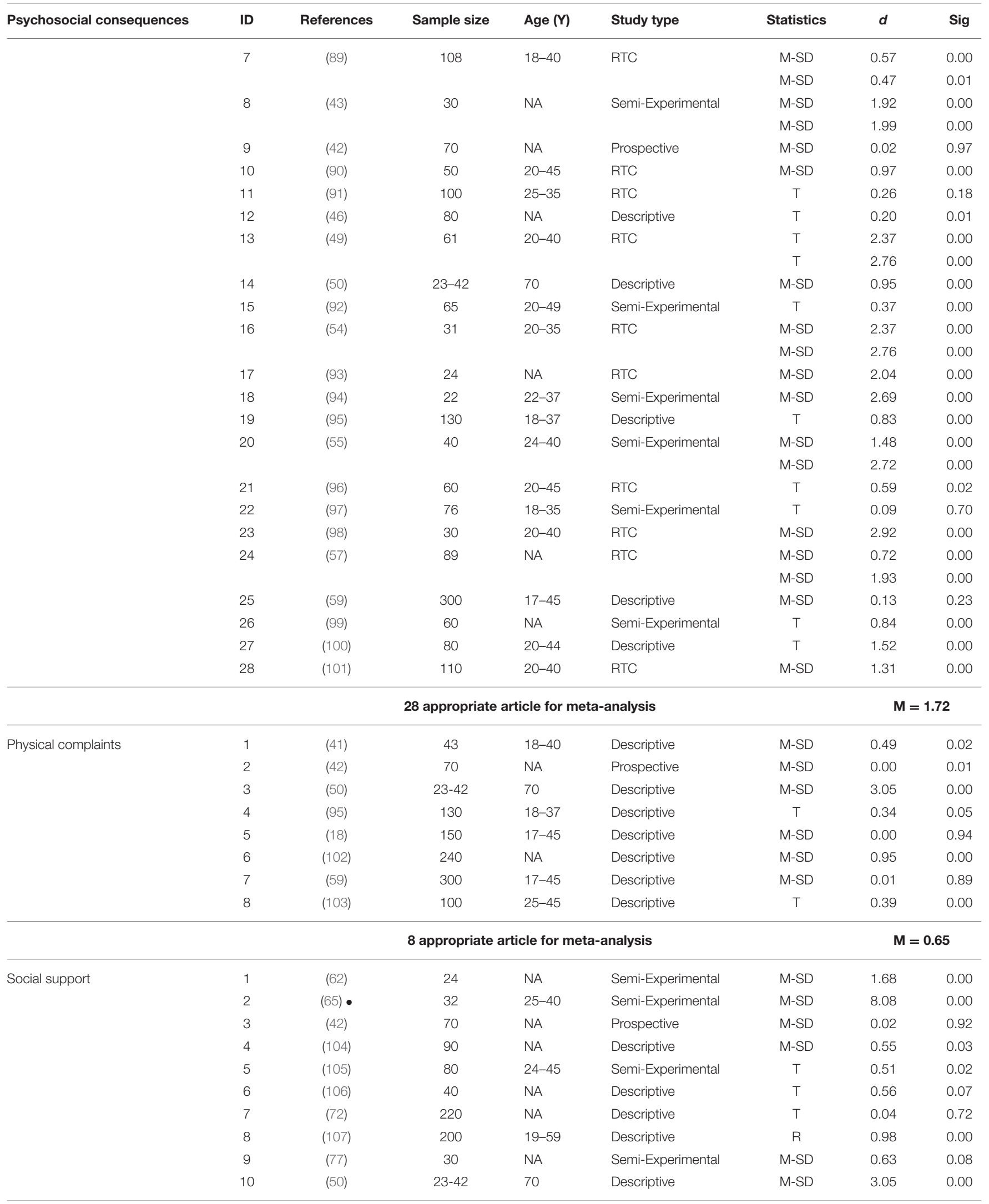


TABLE 1 | Continued

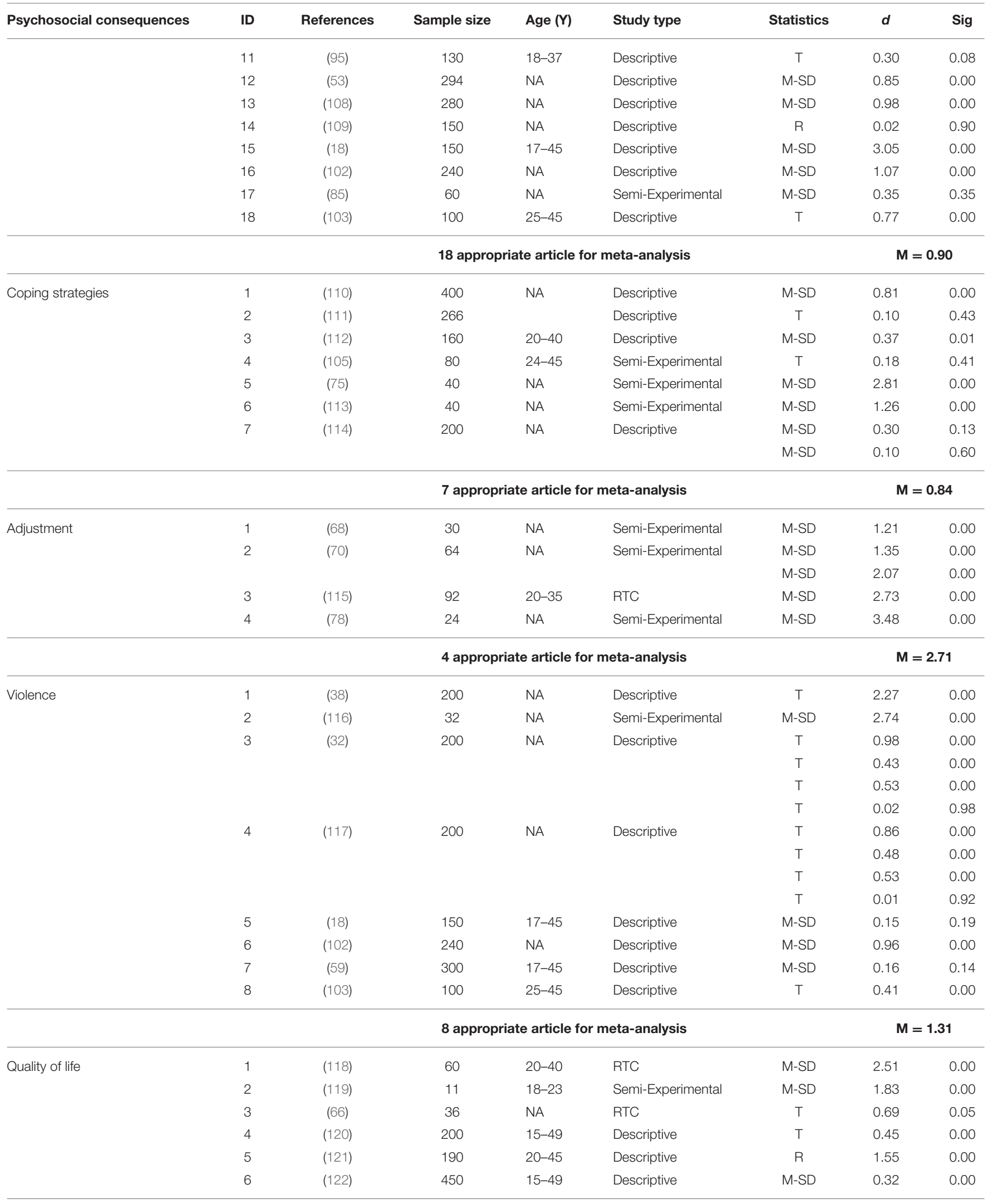


TABLE 1 | Continued

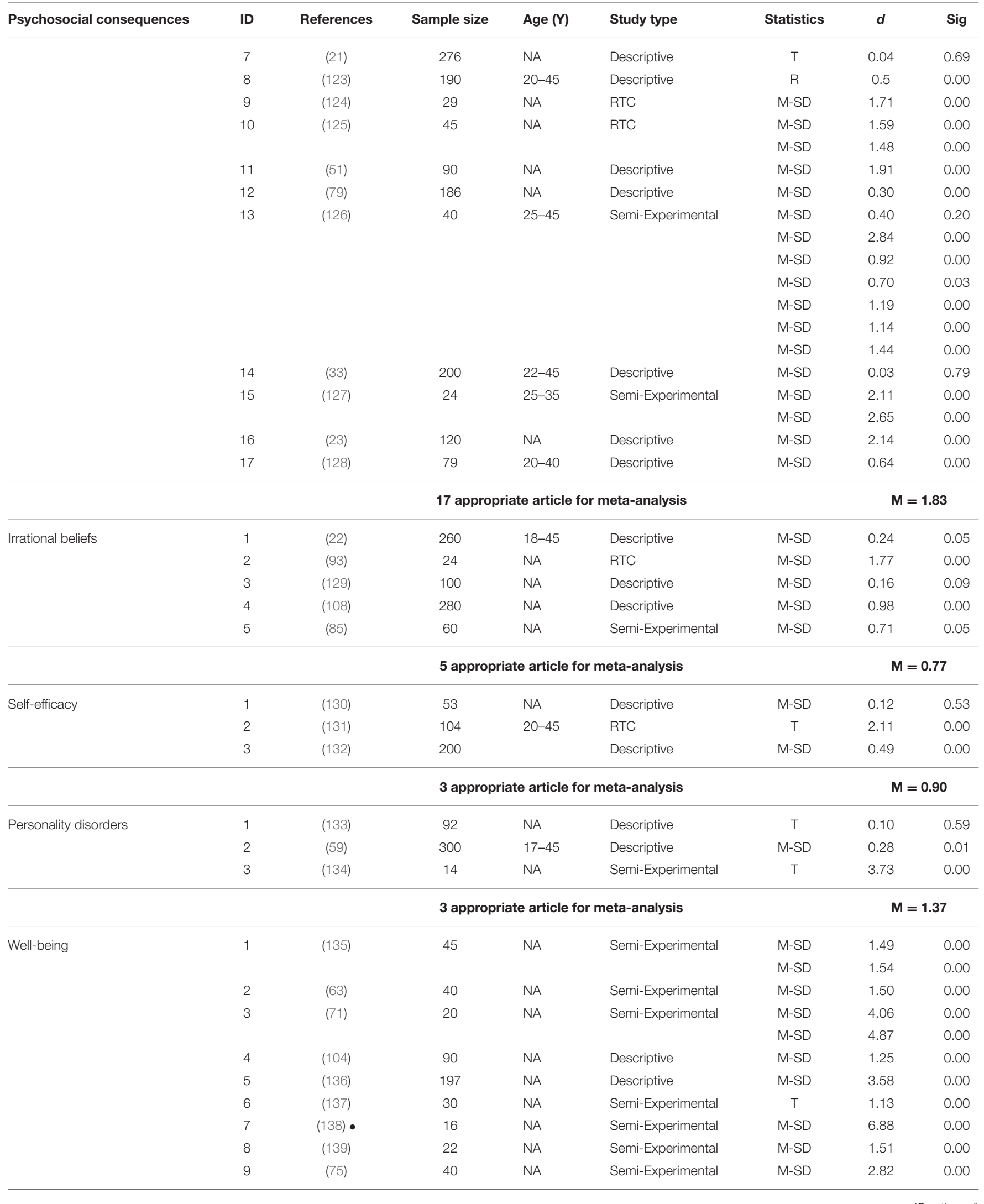


TABLE 1 | Continued

\begin{tabular}{|c|c|c|c|c|c|c|c|c|}
\hline Psychosocial consequences & ID & References & Sample size & Age $(Y)$ & Study type & Statistics & $d$ & Sig \\
\hline & 10 & (125) & 45 & NA & RTC & M-SD & 2.35 & 0.00 \\
\hline & & & & & & M-SD & 1.82 & 0.00 \\
\hline & 12 & (80) & 80 & NA & Descriptive & M-SD & 0.77 & 0.01 \\
\hline & 13 & (94) & 22 & $22-37$ & Semi-Experimental & M-SD & 3.04 & 0.00 \\
\hline & & & & & & M-SD & 3.83 & 0.00 \\
\hline
\end{tabular}

- The research, which had distribution bias, was subsequently discarded.

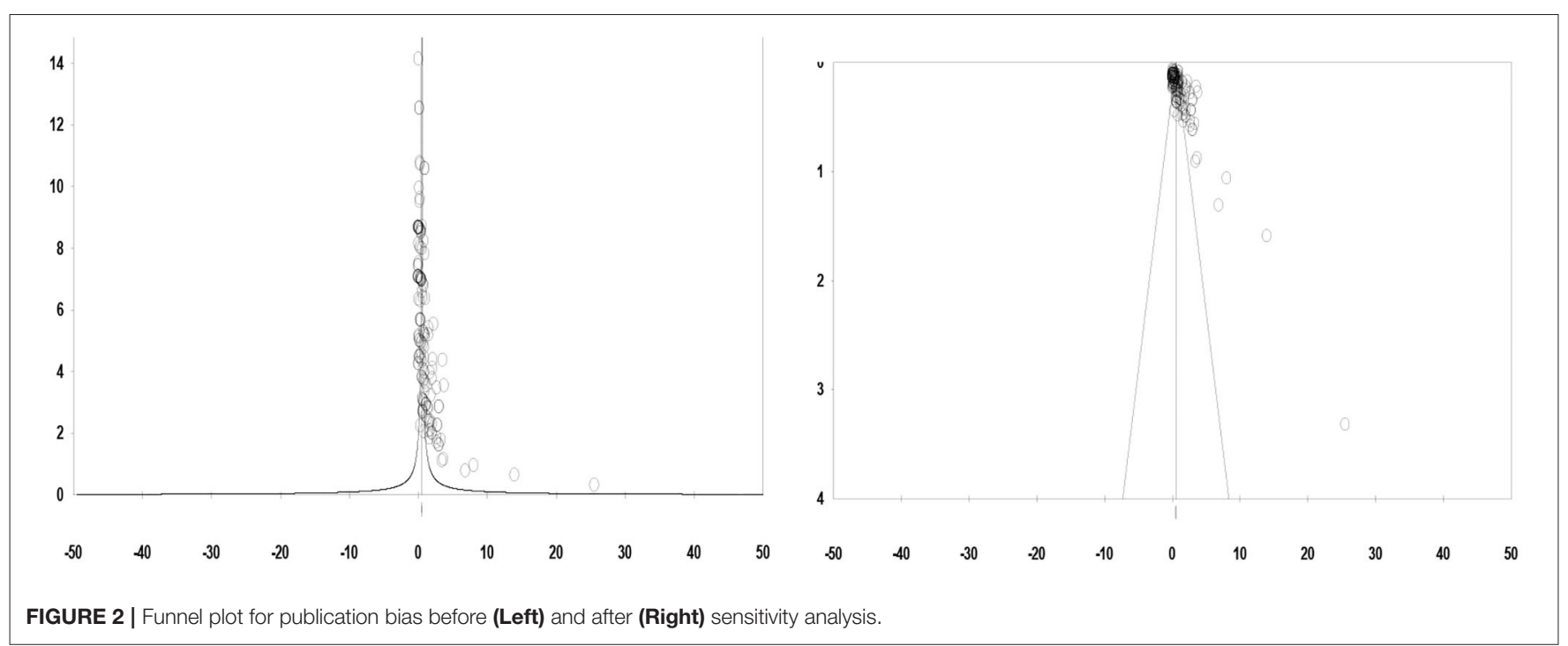

Organization, health is a state characterized by more than just the absence of disease. Therefore, a comprehensive definition of health should also include positive criteria such as welfare and physical, psychological, and social well-being (143). Infertility can decrease well-being by introducing stress in the personal, social, and marital domains. Indeed, when faced with the possibility of infertility, the situation is one of ambiguity: while the desire to bear a child lingers, its fulfillment is unlikely. While this is enough to impose great stress on couples, the side effects of assisted reproductive technology and the possibility of the treatment failing lower the well-being of women with infertility even further.

Adaptation to infertility emerged as the second most significant psychological consequence of infertility in women, with 12 significant effect sizes and a Hedges' effect size of 2.71. Adaptation to infertility refers to the cognitive and behavioral solutions individuals with infertility employ to cope with the crisis (144). The level of adaptation in couples with infertility is influenced by social and personal factors. Research has revealed that factors such as couples' attachment level, relationship quality, personal beliefs, and social support can influence adaptation to infertility (107). Owing to cultural and social reasons as well as religious beliefs, having children is very important for women in Islamic countries, and families generally expect married women to conceive within the first few months of marriage. As previously mentioned, in many traditional cultures, there is a high possibility of the male partners of women with infertility getting remarried (145). This can impose more psychological stress on women, decreasing their adaptation to infertility.

The third psychological aspect affected by infertility is quality of life, with 25 significant effect sizes and a Hedges' effect size of 1.83. In general, infertility and its treatment have negative effects on the quality of life. The severity of these effects is such that researchers have assigned it a distinct definition: fertility quality of life (146). In the context of 21st-century diseases that have a negative effect on quality of life, infertility is ranked third after cancer and cardiovascular diseases (147). Quality of life in women with infertility is related to factors such as economic status, income, and residential region (urban or rural) (148).

The results indicate that depression is the fourth psychological consequence of infertility in women, with 29 significant effect sizes and a Hedges' effect size of 1.80 . At $\sim 30.5 \%$, the prevalence of depression in couples with infertility is higher than in the 
general public. Depression in individuals with infertility is related to a number of factors including gender (being female), duration of infertility, success/failure of previous treatments, and the cause of infertility (i.e., which of the partners is experiencing infertility) (149). In this regard, it is noteworthy that in the intervals between treatments, monthly variations in hopefulness or disappointment induce extensive psychological pressure in individuals with infertility. This pressure is more complex in women compared to men, mainly because women have a yearning for motherhood because of its link to their identity and meaning of life and are generally capable of making great sacrifices for the sake of childbearing. Aside from these psychological factors, having children is considered a source of power in women, in the context of not only the family but also of society. Therefore, when infertility deprives women of this source of power, it is natural that they experience pain and face problems at the familial and societal levels.

The fifth psychological consequence of infertility in women is anxiety, with 33 significant effect sizes and a Hedges' effect size of 1.72. The psychological, social, and financial challenges of infertility and its treatment can intensely influence the lives

TABLE 2 | Effect sizes of psychosocial consequences of infertility in women in Iran.

\begin{tabular}{|c|c|c|c|c|c|}
\hline \multirow{2}{*}{$\begin{array}{l}\text { Psychosocial } \\
\text { outcomes }\end{array}$} & \multirow{2}{*}{$\begin{array}{c}\text { Hedges' } \\
\text { g }\end{array}$} & \multicolumn{4}{|c|}{ Hedges' g and $95 \% \mathrm{Cl}$} \\
\hline & & $-3.00-2.00$ & $1.00-0.00$ & 1.00 & 2.003 .00 \\
\hline Sexual dysfunction & 0.55 & & & & \\
\hline Depression & 1.80 & & & & \\
\hline Marital satisfaction & 1.37 & & & & \\
\hline Anxiety & 1.72 & & & & \\
\hline Physical complaints & 0.65 & & & & \\
\hline Social support & 0.90 & & & & \\
\hline Coping strategies & 0.84 & & & & \\
\hline Adjustment & 2.71 & & & & \\
\hline Violence & 1.31 & & & & \\
\hline Quality of life & 1.83 & & & & \\
\hline Irrational beliefs & 0.77 & & & & \\
\hline Self-efficacy & 0.90 & & & & \\
\hline Personality disorders & s 1.37 & & & & \\
\hline Well-being & 3.10 & & & & \\
\hline Fixed overall & 0.50 & & & & \\
\hline Random overall & 0.83 & & & & \\
\hline
\end{tabular}

$\mathrm{Cl}$, confidence interval. of couples. In the ranking of the worst possible events in a woman's life, infertility was positioned fourth, following death of parents and betrayal by the partner (150). A study in Iran revealed that the prevalence of anxiety in individuals with infertility is $33 \%$, which is significantly higher than in the general population. Further, women have been reported to be 2.26 times more likely than men to report symptoms of anxiety (151).

Marital satisfaction is the sixth psychological consequence of infertility in women, with 41 significant effect sizes and a Hedges' effect size of 1.37 . The stress of infertility affects marital adaptation, marital quality, and marriage stability. Marital quality and satisfaction in couples with infertility is significant, since it facilitates the continuation of infertility treatments and increases their chances of success. It is worth mentioning that the quality of a marital relationship is a major predictor of psychological health in women with infertility, and plays a crucial role in reducing their anxiety and depression levels (152).

The seventh psychological consequence of infertility in women relates to personality disorders, with seven significant effect sizes and a Hedges' effect size of 1.37. An individual's personality is influenced by infertility and its consequences, because people face problems differently and according to their personality traits. One of the factors that influence infertility and its consequences is the personality of individuals, because people with different personality traits face problem differently. Several studies have reported a high prevalence of personality disorders in women with infertility (59).

The eighth psychological consequence of infertility is violence, with 14 significant effect sizes and a Hedges' effect size of 1.31. According to the United Nations' Declaration on the Elimination of Violence Against Women in 1993, violence against women is defined as "any act of gender-based violence that results in physical, sexual, or mental harm or suffering to women, including threats of such acts, coercion, or arbitrary deprivation of liberty, whether occurring in public or private life" (153). Infertility is the main reason for violence against women. In a study conducted on 400 women with infertility in Iran, $61.8 \%$ had experienced domestic violence owing to infertility (145). Moreover, violence against women with infertility is associated with their partner's unemployment and insufficient education, as well as the forced nature of the marriage (154).

Social support is the ninth most influential psychocognitive consequence of infertility in women, with 18 significant effect sizes and a Hedges' effect size of 0.90. Social support is defined as a person's receipt of information, financial aid, health recommendations, and emotional support from individuals in their social network, including partners, relatives, and friends.

TABLE 3 | Hedges' effect sizes of fixed and random models related to psychosocial consequences of infertility.

\begin{tabular}{|c|c|c|c|c|c|c|c|c|}
\hline Model & & Number of effect sizes & Hedges' effect sizes (g) & Standard error & \multicolumn{2}{|c|}{$95 \% \mathrm{Cl}$} & $Z$-value & $P$ \\
\hline & Random & 243 & 1.03 & 0.04 & 0.95 & 1.12 & 23.81 & 0.00 \\
\hline
\end{tabular}


The results of a qualitative study indicated that the four most necessary support categories in couples with infertility are social, financial, spiritual, and informational (155).

Self-efficacy ranks 10th in the list of psychological consequences of infertility in women, with five significant effect sizes and a Hedges' effect size of 0.90 . Self-efficacy stems from the difference between how an individual perceives him/herself (self-concept) and the ideal-self. A small difference between these two leads to high self-efficacy, while larger differences result in low self-efficacy (156). Studies have shown that failure in performing "duties," such as reproduction and fertility, decreases self-confidence. Therefore, having low self-efficacy decreases the level of psychological health and self-efficacy in women with infertility (157).

The use of inefficient coping strategies ranks 11th among the psychocognitive consequences of infertility in women, with eight significant effect sizes and a Hedges' effect size of 0.84 . Coping strategies refer to mindful behaviors and cognitive attempts to manage current or expected stressors and negative events. These strategies are often categorized into two main groups, namely, problem-focused and emotion-focused. While problem-focused strategies employ behaviors such as acting and planning, emotion-focused strategies include expressing emotions and changing expectations (158). The results of Jafarzadeh et al.'s (159) study demonstrated that the cause of infertility is the main factor women without children consider while choosing the strategy to employ. For instance, when the male partner is infertile, women employ problem-focused coping strategies, whereas when they themselves experience infertility, they generally employ emotion-focused coping strategies (159).

Irrational thoughts regarding either having or not having children are the 12th most important psychological consequence of infertility, with five significant effect sizes and a Hedges' effect size of 0.77. Irrational thoughts are the beliefs that individuals learn in life. However, they are not fundamentally realistic and usual. Studies have shown that irrational cognitions regarding childbearing being the essence of a happy life are the main predictors of quality of life in couples with infertility (22).

Physical complaints are the 13th most significant psychocognitive consequence of infertility in women, with 10 significant effect sizes and a Hedges' effect size of 0.65 . Overall, women with infertility have poorer psychological health compared to those who can bear children. A study showed that among the subscales of the Symptom Checklist-90-Revised, the highest mean score among women with infertility was for somatization (50). Stressful events can have a prominent role in the somatization aspect (160). Infertility, reported to be the

\section{REFERENCES}

1. Vander Borght M, Wyns C. Fertility and infertility: definition and epidemiology. Clin Biochem. (2018) 62:2-10. doi: 10.1016/j.clinbiochem.2018.03.012

2. Boivin J, Bunting L, Collins JA, Nygren KG. International estimates of infertility prevalence and treatment-seeking: potential need and demand for infertility medical care. Hum Reprod. (2007) 22:1506-12. doi: 10.1093/humrep/dem046 most challenging event in a woman's life, results in a variety of physical complaints.

Finally, sexual dysfunction is the 14th psychological consequence of infertility, with 17 significant effect sizes and a Hedges' effect size of 0.55 . Negative psychological and physiological consequences of the diagnosis and treatment of infertility can influence sexual functioning and lead to sexual dysfunction. Pregnancy, in the minds of many individuals, is the result solely of sexual intercourse and an indication of intimacy. Therefore, when pregnancy does not occur, it can discourage individuals from having sexual intercourse. On the contrary, in the process of infertility treatment, physicians generally prescribe a certain schedule for couples to have sexual intercourse. When physicians recommend a strict regimen regarding the timing of sexual intercourse and dictate details, it changes from an enjoyable act to a mechanical one (161). As reported, the prevalence of sexual dysfunction in couples with infertility is as high as $87.1 \%(162)$.

The act of fertilization and delivering a healthy child is considered the main event in the life of every couple. However, there is a significant factor that obstructs such joy: infertility. Although both men and women can experience infertility, social (and occasionally religious) pressures imposed on women often result in them carrying the burden of infertility, in turn experiencing psychological and physical problems. Further, therapeutic protocols must be adjusted to decrease, if not eliminate, these consequences.

\section{DATA AVAILABILITY STATEMENT}

All datasets generated for this study are included in the article/supplementary material.

\section{AUTHOR CONTRIBUTIONS}

$\mathrm{HZ}$, HA, and HK contributed conception and design of the study. $\mathrm{HZ}$ and $\mathrm{HA}$ organized the database. $\mathrm{HZ}$ and $\mathrm{HK}$ performed the statistical analysis. $\mathrm{HZ}$ wrote the first draft of the manuscript. $\mathrm{HZ}$ and HA wrote sections of the manuscript. All authors contributed to manuscript revision, read, and approved the submitted version.

\section{ACKNOWLEDGMENTS}

We would like to thank the authors of the studies examined in this meta-analysis. 
infertility in Iran: a population-based study. Glob J Health Sci. (2015) 7:226-32. doi: 10.5539/gjhs.v7n6p226

6. Schweiger U, Schweiger JU, Schweiger JI. Mental disorders and female infertility. Arch Psychol. (2018) 2:1-4. doi: 10.31296/aop.v2i6.73

7. Biringer E, Kessler U, Howard LM, Pasupathy D, Mykletun A. Anxiety, depression and probability of live birth in a cohort of women with self-reported infertility in the HUNT 2 Study and Medical Birth Registry of Norway. J Psychosom Res. (2018) 113:1-7. doi: 10.1016/j.jpsychores.2018.07.001

8. Luk BH-K, Loke AY. The impact of infertility on the psychological wellbeing, marital relationships, sexual relationships, and quality of life of couples: a systematic review. J Sex Marital Therapy. (2015) 41:610-25. doi: 10.1080/0092623X.2014.958789

9. Winkelman WD, Katz PP, Smith JF, Rowen TS, Group, IOPP. The sexual impact of infertility among women seeking fertility care. Sex Med. (2016) 4:e190-e7. doi: 10.1016/j.esxm.2016.04.001

10. Ozan YD, Okumuş H. Effects of nursing care based on Watson's theory of human caring on anxiety, distress, and coping, when infertility treatment fails: a randomized controlled trial. J Caring Sci. (2017) 6:95. doi: $10.15171 /$ jcs. 2017.010

11. Moeenizadeh $M$, Zarif $H$. The efficacy of well-being therapy for depression in infertile women. Int J Fertil Steril. (2017) 10:363-70. doi: 10.22074/ijfs.2016.5087

12. Toftager M, Sylvest R, Schmidt L, Bogstad J, Løssl K, Prætorius L, et al. Quality of life and psychosocial and physical well-being among 1,023 women during their first assisted reproductive technology treatment: secondary outcome to a randomized controlled trial comparing gonadotropin-releasing hormone $(\mathrm{GnRH})$ antagonist and $\mathrm{GnRH}$ agonist protocols. Fertil Steri. (2018) 109:154-64. doi: 10.1016/j.fertnstert.2017.09.020

13. Ma F, Cao H, Song L, Liao X, Liu X. Effects of comprehensive care on mood and quality of life in infertile patients. Int J Clin Exp Med. (2018) 11:4072-9.

14. Karaca A, Unsal G. Psychosocial problems and coping strategies among Turkish women with infertility. Asian Nurs Res. (2015) 9:243-250. doi: 10.1016/j.anr.2015.04.007

15. Mohebbi SF, Ali Mohammadzadeh K. Systematic review of the etiology of the infertility on Iranian domestic published articles between 1999 and 2013. Med Sci J. (2016) 26:1-15.

16. Daibes MA, Safadi RR, Athamneh T, Anees IF, Constantino RE. 'Half a woman, half a man; that is how they make me feel': a qualitative study of rural Jordanian women's experience of infertility. Cult Health Sex. (2018) 20:516-30. doi: 10.1080/13691058.2017.1359672

17. Ergin RN, Polat A, Kars B, Öztekin D. Sofuoglu K, Çalişkan E. Socialstigma and familial attitudes related to infertility. Turk J Obstet Gynecol. (2018) 15:46. doi: 10.4274/tjod.04307

18. Noorbala AA, Ramezanzadeh F, Abedinia N, Naghizadeh MM. Psychiatric disorders among infertile and fertile women. Soc Psychiatry Psychiatr Epidemiol. (2009) 44:587-91. doi: 10.1007/s00127-008-0467-1

19. Abbasi Shavazi MJ, Asgari Khanghah A, Razeghi Nasrabad HB. Women and infertility experience: a Case Study in Tehran. Women Dev Politics. (2005) 3:91-113.

20. Abbasi M, Bavazin F, Mansouri L. Effectiveness of benson relaxation method on reduction of stress and increase of the number and motility of sperms among infertile males. Iranian J Psychiatr Nurs. (2017) 5:22-8. doi: 10.21859/ijpn-05034

21. Abedi G, Darvari SH, Nadighara A, Rostami F. The relationship between quality of life and marriage satisfaction in infertile couples using path analysis. J Mazandaran Univ Med Sci. (2014) 24:184-93.

22. Abhar Zanjani F, Khajeh-Mirza V, Seyyedi M, Shahabizadeh F, Dastjerdi R, Bahreinian A. Assessment on relationship beliefs and marital burnout among fertile and infertile couples. J Fundam Mental Health. (2015) 17:81-6.

23. Abolqasemi A, Sheybani H, MohammadNarimān I, Masoud G. Relationship of androgyny and neuroticism with quality of life in infertile and fertile women. Women Stud. (2009) 6:47. doi: 10.22051/jwsps. 2008.1314

24. Barghi Irani Z, Zohreh P, Fatemeh P. The role of the self-esteem, perceived stress, alexithymia and cognitive avoidance on the sexual function of the fertilized and unfertilized women. J Urmia Nurs Midwifery Facul. (2017) 15:95-106.
25. Masoumi SZ, Garousian M, Khani S, Oliaei SR, Shayan A. Comparison of quality of life, sexual satisfaction and marital satisfaction between fertile and infertile couples. Int J Fertil Steril. (2016) 10:290. doi: 10.22074/ijfs.2016.5045

26. Mirblouk F, Asgharnia M, Solimani R, Fakor F, Salamat F, Mansoori S. Comparison of sexual dysfunction in women with infertility and without infertility referred to Al-Zahra Hospital in 2013-2014. Int J Reprod Biomed. (2016) 14:117. doi: 10.29252/ijrm.14.2.117

27. Zare Z, Amirian M, Golmakani N, Mazlom R, Ahangar ML. Sexual dysfunction in infertile women. International Journal of Reproductive BioMedicine. (2016) 14:89. doi: 10.29252/ijrm.14.2.89

28. Fahami F, Pahlavanzadeh S, Asadi M. Efficacy of communication skills training workshop on sexual function in infertile women. Iran $J$ Nurs Midwifery Res. (2015) 20:179.

29. Khodarahimi S, Hosseinmirzaei S, Bruna MMO. The role of infertility in mental health, psychological distress and sexual dysfunction in a sample of Iranian women. Women Therapy. (2014) 37:178-94. doi: 10.1080/02703149.2014.850331

30. Zabihi rigcheshme M, Mirzaian B, Hasanzade R, Shahidi M. Comparing sexual attitudes of fertile and infertile couples. J Mazandaran Univ Med Sci. (2012) 21:271-81.

31. Pakpour AH, Yekaninejad MS, Zeidi IM, Burri A. Prevalence and risk factors of the female sexual dysfunction in a sample of infertile Iranian women. Arch Gynecol Obstet. (2012) 286:1589-1596. doi: 10.1007/s00404-012-2489-x

32. Tabrizi G, Tabrizi S, Vatankhah M. Female infertility resulting in sexual disorders and wife abuse. Pazuhesname. (2010) 1:1-9.

33. Nourani S, Jonaidy E, Shakeri MT, Mokhber N. Sexual satisfaction in fertile and infertile women attending state clinics in Mashad. J Reprod Infertil. (2009) 10:269.

34. Bahrami N, Sattarzadeh N, Koochaksariie FR, Ghojazadeh M. Comparing depression and sexual satisfaction in fertile and infertile couples. J Reprod Infertil. (2007) 8:52-60.

35. Besharat MA, Hoseinzadeh Bazargani. R. A comparative study of fertile and infertile women's mental health and sexual problems. Iran J Psychiatry Clin Psychol. (2006) 12:146-53.

36. Satarzadeh N, Bahrami N, Ranjbar K, Saraei F, Ghojazadeh M. Comparison of sexual satisfactory and depression between sterile and unsterile couples refer to Alzahra research and education center, Tabriz. Yafteh. (2007) 9:17.

37. Besharat MA, Mirzamani SM. The relationship between attachment styles and sexual problems among infertile couples. Dev Pscychol. (2006) 2:101.

38. Shadkam N, Bahrani M, Pooladi Reyshahri A. Comparison of psychological situation (depression, aggression) infertile women than in fertile women in Shiraz. Irijournals. (2017) 3:63-72.

39. Hosseini M, Neissi AK, Davodi I, Mehrabizade-Honarmand M, Zargar Y. The effectiveness of holistic-oriented psychological intervention on health psychology in infertile women undergoing IVF. J Clin Psycol. (2017) 9:47-54.

40. Jamshidian-Qalehshahi P, Aghaei A, Golparvar M. Comparing the effect of iranian positive therapy and acceptance -commitment therapy on depression, anxiety and stress of infertile women in Isfahan city. $J$ Health Promot Manage. (2017) 6:8-16. doi: 10.21859/jhpm-07032

41. Rahimi Ahmad Abadi S, Hejazi A, Attaran A, Rahimi Ahmad Abadi Z. Comparing the indicators of mental health and parenting practices in fertile and infertile women applying for adoptions. Iran J Forensic Med. (2017) 22:281-90.

42. Zivaridelavar M, Kazemi A, Kheirabadi GR. The effect of assisted reproduction treatment on mental health in fertile women. J Educ Health Promot. (2016) 5:1-5. doi: 10.4103/2277-9531.184552

43. Jamshidian-Qalehshahi P, Aghaei A, Golparvar M. Investigating the effectiveness of Iranian-Islamic positive therapy on depression, anxiety, and stress of infertile women. J Isfahan Med School. (2016) 35:70-6.

44. Rahimi R, Afsharinia K, Golmohammadian M, Jarareh J. Efficacy psychodrama the on reducing depression in infertile women. Res Clin Psychol Counsel. (2016) 5:65.

45. Golmohammadian M, Naeimi M, Choupani M. The effectiveness of listening to the Holy Quran in improving the depression of infertile women. JIQS. (2015) 6:99-109.

46. Bakhtiari M, Anamagh AN, Khayatan T, Nouri P, Asl STS. Depression, anxiety, happiness and satisfaction with life among fertile and infertile women. Int J Life Sci. (2014) 8:10-4. doi: 10.3126/ijls.v8i4.10892 
47. Toozandehjani H, Soltanzadeh Mezreji H. Efficacy of group reality therapy on depression in infertile women before treatment with assisted reproductive techniques IUI. J Res Behave Sci. (2014) 12:184-93. doi: 10.5901/mjss.2016.v7n3s3p127

48. Talaei A, Kimiaei SA, Borhani Moghani M, Moharreri F, Talaei A, Khanghaei R. Effectiveness of group cognitive behavioral therapy on depression in infertile women. Iran J Obstet Gynecol Infertil. (2014) 17:1-9. doi: 10.22038/ijogi.2014.2774

49. Mosalanejad L, Abdolahifard K, Jahromi MG. Therapeutic vaccines: hope therapy and its effects on psychiatric symptoms among infertile women. Glob J Health Sci. (2014) 6:192. doi: 10.5539/gjhs.v6 n1p192

50. Amani-Vamarzani S, Dusti Y, Hassanzadeh R. Psychological disorders among women with Primary Infertility and fertile women. Int Res J Appl Basic Sci. (2013) 4:720-3.

51. Zamani SN, Ghasemi M, Jokar E, Moghadam NK. Comparison of depression and life quality of fertile and infertile women and those with frequent abortions. J Babol Univ Med Sci. (2013) 15:78-83. doi: 10.18869/acadpub.jbums.15.6.78

52. Aghayousefi A, Zare H, Choobsaz F, Motiei G. The effect of coping therapy on hopelessness of infertile women. Int J Behav Sci. (2011) 5:119.

53. Jamilian M, Rafiei M, Jamilian HR, Esmkhani A. The comparison of general health between fertile and infertile women of Arak City in 2010. Arak Med Univ J. (2012) 14:27.

54. Mosalanejad L, Koolaee AK, Jamali S. Effect of cognitive behavioral therapy in mental health and hardiness of infertile women receiving assisted reproductive therapy (ART). Iran J Reprod Med. (2012) 10:483.

55. Hamid N. The effectiveness of stress management based on cognitivebehavior method on depression, anxiety and fertilization of infertile women. Int J Behav Sci. (2011) 5:55.

56. Motiei G, Aghayousefi AR, Choobsaz F, Shaghaghi F. Effectiveness of the coping therapy on loneliness feel of infertile women. J Appl Psychol. (2012) 5:85-98.

57. Faramarzi M, Alipor A, Esmaelzadeh S, Kheirkhah F, Poladi K, Pash $\mathrm{H}$. Treatment of depression and anxiety in infertile women: cognitive behavioral therapy versus fluoxetine. J Affect Disord. (2008) 108:159-64. doi: 10.1016/j.jad.2007.09.002

58. Sobhaninejad M, Homaei R. Comparison of stress and depression in infertile and fertile couples. Daneshvar(medicine) Shahed Univ. (2006) 14:13-22.

59. Noorbala AA, Ramezanzadeh F, Abedinia N, Bagheri Yazdi SA. Study of psychiatric disorders among fertile and infertile women and some predisposing factors. J Fam Reprod Health. (2007) 1:6-11.

60. Izadi N, Sajjadian I. The relationship between dyadic adjustment and infertility-related stress: the mediated role of self-compassion and selfjudgment. Iran J Psychiatr Nurs. (2017) 5:15-22. doi: 10.21859/ijpn-05023

61. Danesh E, Aminalroayaei P, Nooripour Liavoli R. The relationship between resiliency, psychological well-being and marital satisfaction of infertile couples undergoing in vitro fertilization. Soc Health. (2017) 4:170-8. doi: $10.22037 /$ ch.v4i3.13681

62. Sadri Damirchi E, Ali S, Tarvirdizadeh H. The effect of emotional-focused couple therapy on the infertile couple's quality of relationship, marital conflict, and intimacy. J Fam Counsel Psychother. (2017) 7:125-45.

63. Khakpour M, Nejat H, Karimian F, Mehrafarid M, Mortazavi S, Chenari T. Effect of fordyce happiness model on hardiness and marital adjustment in infertile couples. J Nurs Educ. (2017) 6:51-60. doi: 10.21859/jne-06026

64. Sayadpour Z, Sayadpour M. Comparison marriage satisfaction, anxiety and assertiveness in fertile and infertile women. J Psychol Sci. (2017) 15:532.

65. Adl HA, Shafiabadi A, Pirani Z. The effectiveness of group therapy based on quality of life on marital intimacy in infertile women. Arak Med Univ J. (2017) 19:59-71.

66. Seyedi ST, Sadeghi K, Bakhtiari M, Ahmadi SM, Anamagh AN, Khayatan T. Effect of group positive psychotherapy on improvement of life satisfaction and the quality of life in infertile woman. Int J Fertil Steril. (2016) 10:105. doi: 10.22074/ijfs.2016.4775

67. Solati K, Ja'Farzadeh LB, Hasanpour A. The effect of stress management based on group cognitive-behavioural therapy on marital satisfaction in infertile women. J Clin Diagn Res. (2016) 10:VC01. doi: $10.7860 / J C D R / 2016 / 17836.8077$
68. Samadi H, Doostkam M. Investigating the effectiveness of Acceptance and Commitment Therapy (ACT) on marital compatibility in infertile women. Thought Behav Clin Psychol. (2016) 11:67.

69. Poorheidari M, Alijani F, Aghayan SS, Keramat A, Masoumi SZ, Asadi $Z$. The effect of relationship enrichment training on marital intimacy among infertile couples with domestic violence. J Isfahan Med School. (2016) 34:1187-96.

70. Miri MR, Alizadeh M, Moasheri N, Ataee M, Moodi M. The effects of relationship enrichment program on compatibility and marital satisfaction of infertile couples. J Health Literacy. (2016) $1: 53-60$.

71. Dargahi S, Mohsenzade F, Zahrakar K. The effect of positive thinking training on psychological well-being and perceived quality of marital relationship on infertile women. Positive Psychol Res. (2016) 1:45-58.

72. Shahverdi J, Ahmadi SM Sadeghi K, Bakhtiari M, Rezaei M, Veisy F, et al. A comparative study of the level of mental health, happiness, inferiority feelings, marital satisfaction and marital conflict in fertile and infertile women in Kermanshah. J Clin Res Paramed Sci. (2016) 4:277-5.

73. Shahverdi J, Rezaei M, Ayazi Roozbahani M, Sadeghi K, Bakhtiari M, Shahverdi M. Relationship between general health with happiness, inferiority feeling and marital conflict in Borujerd city infertile women. Adv Nurs Midwifery. (2016) 25:47-54.

74. Ghezelbashyan Z, Arefi M. Material intimacy and material satisfaction in infertile and normal women. J Clin Res Paramed Sci. (2016) 4:360-7.

75. Dargahi S, Zeraati M, Ghamari Givi H, Ayadi N, Haghanni M. The effectiveness of emotion regulation training on emotional well- being and marital satisfaction of infertile women. Iran J Nurs. (2015) 28:151-62. doi: 10.29252/ijn.28.93.94.151

76. Zare Z, Golmakani N, Amirian M, Mazloum SR, Laal Ahangar M. Comparison of marital satisfaction in fertile and infertile couples and its relationship with sexual problems. Iran J Obstet Gynecol Infertil. (2015) 18:1-10. doi: 10.15171/jcs.2017.026

77. Kermanshahi F, Shafiabadi A. Examine the effects of adleri on improving communication patterns infertile women. J Educ Res. (2014) 9:92-112.

78. Soltani M, Shaeiri MR, Roshan R. The effects of emotional focused therapy on increasing the marriage suitability of barren couples. Int J Behav Sci. (2013) 6:383.

79. Amanelahifard A, Nikbakht R, Hoseini MA, Ahmadi Fakhr S, Hoseini Z. The comparison of marital satisfaction and quality of life between fertile and infertile women. J Appl Counsel. (2012) 2:75-88.

80. Hatamloye Saedabadi M, Hashemi Nosratabad. T. The comparison of psychological well-being and marital satisfaction in the fertile and infertile women. J Health Psychol. (2012) 1:17-28.

81. Latifnejad Roudsari R, Karami Dehkordi A, Allah Esmaili H, Mousavifar $\mathrm{N}$, Aghamohamadian Sherbaf H. The relationship between body image and marital adjustment in infertile women. Iran J Obstet Gynecol Infertil. (2012) 14:9. doi: 10.22038/IJOGI.2011.6012

82. Vizheh M, Pakgohar M. The effect of Infertility consultation sessions on the Marital relationship amongst infertile women. Nurs Dev Health. (2010) 1:76-89.

83. Choobforoushzade A, Kalantari M, Molavi H. The effectiveness of cognitive behavioral stress management therapy on marital satisfaction in infertile women. J Fundam Mental Health. (2010) 12:596. doi: 10.22038/jfmh.2010.1041

84. Jonaidy E, Noorani Sadodin S, Mokhber N, Shakeri MT. Comparing the marital satisfaction in infertile and fertile women referred to the public clinics in Mashhad in 2006-07. Iran J Obstet Gynecol Infertil. (2009) 12:7. doi: 10.22038/ijogi.2012.5717

85. Nilforoushan P, Ahmadi SA, Abedi MR, Ahmadi SM. Studying the effect of cognitive - behavioral counseling, based on Interacting Cognitive Subsystems approach on attitude towards infertility of infertile couples. J Fam Res. (2006) 2:21.

86. Mazaheri M, Kayghobadi F, Imani ZF, Ghashang N, Pato M. Problem solving strategies and marital adjustment in infertile and fertile couples. J Reprod Infertil. (2001) 2:22-33.

87. Sheikhsajadieh M, Atashpuor SH. Effectiveness of dialectical behavioral group therapy on psychological distress in infertile women in Isfahan. Knowl Res Appl Psychol. (2017) 18:23-9. 
88. Ghelichi F, Roshan R, Khodabakhshi Kolaee A. Comparing of maternalfetal attachment and pregnancy anxiety in surrogate women and normal pregnancy. Iran J Obstet Gynecol Infertil. (2017) 19:46-53. doi: 10.22038/ijogi.2017.8421

89. Ghasemi Gojani M, Kordi M, Asgharipur N, Amirian M, Esmaeli H, Eskandarnia E. Comparing the effect of positive reappraisal coping intervention on anxiety of waiting period in IUI treatment using problemsolving skills training. J Mazandaran Univ Med Sci. (2017) 27:111-23.

90. Rabeipour S, Ordoni Avval Z, Arefi M, Behroozilak T. The effectiveness of group counseling by collaborative approaches on specific stress in infertile women. J Urmia Nurs Midwifery Facul. (2016) 14:56-65.

91. Dokht Nekavand M, Mobini N, Roshandel S, Sheikhi A. A survey on the impact of relaxation on anxiety and the result of IVF in patients with infertility that have been referred to the infertility centers of Tehran university of medical sciences during 2012-2013. J Urmia Nurs Midwifery Facul. (2015) 13:605-12.

92. Hasanzadeh LM, Tarkhan M, Taghizadeh ME. Effectiveness of stress inoculation training on perceived stress in pregnant women with infertility. J Holis Nurs Midwifery. (2013) 23:27-34.

93. Shahrestani M, Qanbari BA, Nemati SH, Rahbardar H. The effectiveness of mindfulness based cognitive group therapy (MBCT) on improving perceived infertility-related stress and irrational parenthood cognitions among infertile women undergoing IVF treatment. Iran J Obstet Gynecol Infertil. (2012) 15:28. doi: 10.22038/ijogi.2012.6158

94. Zarif Golbar Yazdi H, Aghamohammadian Sharbaf H, Mousavifar N, Moeenizadeh M. The effectiveness of well-being therapy on stress, and psychological well-being in infertile women. Iran J Obstet Gynecol Infertil. (2012) 15:49. doi: 10.22038/ijogi.2012.5744

95. Tamannai Far MR. A Comprative Study of mental health, marital adjustment and coping responses among fertile-infertile women. Biannual Peer Rev J Clin Psychol Pers. (2012) 4:51-60.

96. Latifnejad Roudsari R, Rasolzadeh Bidgoly M, Mousavifar N, Modarres Gharavi M. The effect of collaborative counseling on perceived infertilityrelated stress in infertile women undergoing IVF. Iran J Obstet Gynecol Infertil. (2011) 14:22. doi: 10.22038/ijogi.2015.5766

97. Valiani M, Abediyan S, Ahmadi SM, Pahlavanzadeh S, Hassanzadeh A. The effect of relaxation techniques to ease the stress in infertile women. Iran J Nurs Midwifery Res. (2010) 15:259.

98. Hamzehpoor Haghighi T, Ghorban Shirodi S, Tizdast T. The effect of cognitive-behavioral therapy in reducing the anxiety of infertile women. Women Fam Stud. (2009) 2:27-40.

99. Gharaie V, Mazaheri M, Sahebi A, Peivandi S, Hossinei MA. Effect of behavioral-cognitive education on reduction of anxiety in women with primary infertility who undergo GIFT and ZIFT. J Reprod Infertil. (2004) 5:170-81.

100. Pahlavani H, Malakouti K, Shahrokh Tehrani Nejad E. Stressors, their coping strategies, and relation to mental health in infertile individuals. Iran Psychiatry Clin Psychol. (2003) 7:79.

101. Heidari P, Latifnejad R, Sahebi A, Jahaniyan M, Mazloum S. Impact of cognitive behavior therapy on anxiety level of primary infertile women undergoing IUI. J Reprod Infertil. (2002) 3:40-52.

102. Taghva N, Fathi Ashtiyani A. A comparison between psychological features of fertile and infertile individuals. Thought Behav Clin Psychol. (2009) 3:45.

103. Najmi B, Ahmadi S, Ghassemi G. Psychological characteristics of infertile couples referring to Isfahan Fertility and Infertility Center (IFIC). J Reprod Infertil. (2001) 2:40-6.

104. Saraian E, Sajjadian I. Comparison of perceived social support and psychological well-being between pregnant women with surrogacy, assisted reproductive technology (ART) and natural fertility. Iran J Psychiatr Nurs. (2016) 4:1-10. doi: 10.21859/ijpn-04021

105. Fadaee M, Rahimi Kian F, Damghanian M, Shahrokhnezad Tehrani A, Mehran A. Effect of continuous care model on emotional health and social connection aspects of quality of life of infertile women. J Clin Nurs Midwifery. (2016) 5:52-63.

106. Bayani F, Aghayari T, Hoseini Y, Dankob G. Comparison of social health status among fertile and infertile women. Sociol Lifestyle Manag. (2016) 1:67-97.
107. Besharat MA, Lashkari M, Rezazadeh MR. Explaining adjustment to infertility according to relationship quality, couples' beliefs and social support. Fam Psychol. (2015) 1:41-54.

108. Fatemi AS, Younesi SJ, Azkhosh M, Askari A. Comparison of dysfunctional attitudes and social adjustment among infertile employed and unemployed women in Iran. Int J Psychol. (2010) 45:140-6. doi: 10.1080/00207590903281096

109. Ehsanpour S, Mohsenzadeh N, Kazemi A, Yazdani M. The relation between social support and stress in treatment of infertility in infertile couples referred to infertility centers of Isfahan in 2007. Iran J Nurs Midwifery Res. (2009) 14:51-5.

110. Azizi A. Regulation of emotional, marital satisfaction and marital lifestyle of fertile and infertile. Rev Eur Stud. (2018) 10:14. doi: 10.5539/res.v10n1p14

111. Yazdani F, Kazemi A, Fooladi MM, Samani HRO. The relations between marital quality, social support, social acceptance and coping strategies among the infertile Iranian couples. Eur J Obstet Gynecol Reprod Biol. (2016) 200:58-62. doi: 10.1016/j.ejogrb.2016.02.034

112. Jebraeili H, Hashemi J, Nazemi A. A comparative study of resilience, meta-emotional beliefs, and psychological well-being in fertile and infertile women. J Fundam Mental Health. (2016) 18:259-64. doi: $10.22038 /$ jfmh.2016.7483

113. AghaYousefi A, Choubsaz F, Shaghaghi F, Motiei G. The effect of coping techniques training on coping strategies of infertile women in Kermanshah. J Kermansha Univ Med Sci. (2012) 16:155.

114. Solati K, Danesh A, Ganji F, Abedi A. Comparison of self-esteem and coping responses in infertile and fertile couples from Shahrekord, during 2003-2004. J Shahrekord Univ Med Sci. (2006) 7:16.

115. Kheirkhah M, Vahedi M, Jenani P. The effect of group counseling on infertility adjustment of infertile women in Tabriz Al-Zahra clinic. Iran J Obstet Gynecol Infertil. (2014) 17:7-14. doi: 10.22038/ijogi.2014.3385

116. Oraki M, Vaziri Nasab B, Alipour A. The effectiveness of cognitive-behavioral intervention for anger management on mental health of infertile women. Urmia Med J. (2015) 26:652.

117. Etesami Pour P, Banihashemian K. Comparison of sex disorders and couple abuse among fertile and infertile women. Birjand Univ Med Sci. (2011) 18:10.

118. Rahmani Fard T, Kalantarkousheh SM, Faramarzi M. The effect of mindfulness-based cognitive psychotherapy on quality of life in infertile women. Hayat. (2017) 23:277-89.

119. Omidali F. Effects of Pilates training on the quality of life in polycystic ovary syndrome women. Iran J Rehab Res Nurs. (2017) 2:49-58.

120. Almasi M, Mahmoudiani S, Ghasemi T. Comparing spiritual health and quality of life among fertile and infertile women. Iran J Nurs. (2015) 28:8795. doi: 10.29252/ijn.28.93.94.87

121. Hosseini R, Alijanpour Agamaleki M, Mehrabi T, Ziraki Dana A, Dadkhah A. The relationship between existential dimension of spiritual well-being and quality of life in women with infertility. J Health Care. (2014) 16:53-60.

122. Direkvand Moghadam A, Delpisheh A, Direkvand MA. Compare the quality of life in fertile and infertile women attending public and private centers in Ilam in 2013. Adv Nurs Midwifery. (2014) 24:39-44.

123. Mehrabi T, Alijanpoor Aghamaleki M, Sadat Hosseiny R, Ziraki Dana A, Safaee Z. A study on the relationship between spiritual well-being and quality of life in infertile women referred to infertility centers in Isfahan. J Urmia Nurs Midwifery Facul. (2014) 12:562-7.

124. Narimani M, Alamdari E, Abolghasemi A. The study of the efficiency of acceptance and commitment-based therapy on the quality of infertile women's life. J Fam Counsel Psychother. (2014) 4:387.

125. Zarbakhsh Bahri M, Shoahasani Z, Zahiri Z, Hafshjani F, Khademi M. Effects of stress management training and problem solving on quality of life and life expectancy among infertile women. Pajouhan Sci J. (2013) 11:1-0.

126. Askari P, Saedi S. Effectiveness of stress-inoculation training (SIT) in infertile women's quality of life. Thought Behav Clin Psychol. (2012) 6:19-28.

127. Choobforoushzade A, Kalantari M, Molavi H. The effectiveness of cognitive behavioral stress management therapy on quality of life in infertile women. Iran J Obstet Gynecol Infertil. (2011) 14:14. doi: 10.22038/ijogi.2011.5789

128. Nilforoushan P, Latifi Z, Abedi MR, Ahmadi SA. Comparison of quality of life and its various dimensions in fertile and infertile women. J Behav Sci Res. (2007) 4:66-70. 
129. Honarparvaran N, Qudery Z, Taghva M, Zandi ghashghaee K. A study on Irrational Beliefs and Emotions Associated with the Sexual Desire of Infertile Women. Armaghane Danesh. (2013) 17:514-21.

130. Taghizadeh Z, Oman-Samani R, Kazemnejad A, Reisi M. Self-concept and self-discrepancy among the women receiving and donating oocyte. Hayat. (2015) 21:50-62.

131. Jamshidimanesh M, Alimanesh N, Behbodi Moghaddam Z, Haghani H. Effect of an Educational package on self-efficacy of infertile women. Payesh. (2015) 14:227-37.

132. Zare E, Bahrami N, Soleimani MA. Comparison of self-esteem in fertile and infertile women. Iran Journal of Nursing. (2014) 27:14-21. doi: 10.29252/ijn.27.90.91.14

133. Rasti M, Hasanzade R, Mirzaian B. Comparison of personality traits and happiness among fertile and infertile women. Fam Health. (2012) 1:27-33.

134. Manouchehri K, Zandipour T, Pourshahriari M, Mirdamadi SR. Investigating the effectiveness of emotional cognitive-behavioral group counseling on the mental health of infertile women. News Res Counsel. (2007) 5:9-22.

135. Jamshidian-Qalehshahi P, Aghaei A, Golparvar M. Comparison of effect Iranian - Islamic positive therapy with acceptance and commitment therapy on psychological well-being of infertile women in Isfahan city. J Urmia Nurs Midwifery Facul. (2017) 15:48-57.

136. Gharibi J, Gharibi H, Mohammadian K. Comparison of happiness, meaning of life and psychological stubbornness in fertile and infertile women in Sanandaj. Women Fam Stud. (2016) 8:103-16.

137. Agha Yusefi A, Dahestani M, Abaspour P, Bakhtiari M, Vafaee S. Evaluation of the effectiveness of quality of life therapy (QOLT) on individual wellbeing and happiness of infertile women. Mediterr J Soc Sci. (2015) 6:87. doi: 10.5901/mjss.2015.v6n6s6p87

138. Jalili Nikoo S, Rezaei Z, Nejati Nezhad N, Ghasemi Jobaneh R, Nooryan K. Effectiveness of existential psychotherapy in increasing the resiliency of infertile women. Armaghane Danesh. (2015) 20:453-9.

139. Behzadpoor S, Motahhari ZS, Vakili M, Sohrabi F. The effect of resilience training on increasing psychological well-being of infertile women. Ilam Univ Med Sci. (2015) 23:131-42.

140. Hashemi F, Alipour A, Phili A. The effectiveness of cognitive behavioral stress management therapy on happiness among infertile women. Armaghane Danesh. (2014) 18:678-86.

141. Choobforoushzade A, Kalantari M, Molavi H. The effectiveness of cognitive behavioral stress management on subjective well-being in infertile women. $J$ Clin Psycol. (2009) 1:1.

142. Borenstein M, Hedges LV, Higgins JP, Rothstein HR. A basic introduction to fixed-effect and random-effects models for meta-analysis. Res Synth Methods. (2010) 1:97-111. doi: 10.1002/jrsm.12

143. Huber M, Knottnerus JA, Green L, van der Horst H, Jadad AR, Kromhout D, et al. How should we define health? BMJ. (2011) 343:d4163. doi: 10.1136/bmj.d4163

144. Arslan-Özkan I, Okumuş H, Buldukoglu K. A randomized controlled trial of the effects of nursing care based on Watson's Theory of Human Caring on distress, self-efficacy and adjustment in infertile women. J Adv Nurs. (2014) 70:1801-12. doi: 10.1111/jan.12338

145. Ardabily HE, Moghadam ZB, Salsali M, Ramezanzadeh F, Nedjat S. Prevalence and risk factors for domestic violence against infertile women in an Iranian setting. Int J Gynecol Obstet. (2011) 112:15-7. doi: 10.1016/j.ijgo.2010.07.030

146. Dural O, Yasa C, Keyif B, Celiksoy H, Demiral I, Yuksel Ozgor B, et al. Effect of infertility on quality of life of women: a validation study of the Turkish FertiQoL. Hum Fertil. (2016) 19:186-91. doi: 10.1080/14647273.2016.1214754

147. Qiao J, Feng HL. Assisted reproductive technology in China: compliance and non-compliance. Transl Pediatr. (2014) 3:91. doi: 10.3978/j.issn.2224-4336.2014.01.06
148. Namdar A, Naghizadeh MM, Zamani M, Yaghmaei F, Sameni MH. Quality of life and general health of infertile women. Health Qual Life Outcomes. (2017) 15:139. doi: 10.1186/s12955-017-0712-y

149. Omani-Samani R, Maroufizadeh S, Almasi-Hashiani A, Amini P. Prevalence of depression and its determinant factors among infertile patients in Iran based on the PHQ-9. Middle East Fertil Soc J. (2018) 23:460-3. doi: 10.1016/j.mefs.2018.03.002

150. Lykeridou K, Gourounti K, Deltsidou A, Loutradis D, Vaslamatzis G. The impact of infertility diagnosis on psychological status of women undergoing fertility treatment. J Reprod Infant Psychol. (2009) 27:223-37. doi: 10.1080/02646830802350864

151. Maroufizadeh S, Ghaheri A, Almasi-Hashiani A, Mohammadi M, Navid B, Ezabadi Z, et al. The prevalence of anxiety and depression among people with infertility referring to Royan Institute in Tehran, Iran: a crosssectional questionnaire study. Middle East Fertil Soc J. (2018) 23:103-6. doi: 10.1016/j.mefs.2017.09.003

152. Alipour Z, Kazemi A, Kheirabadi G, Eslami, A.-A. Relationship between marital quality, social support and mental health during pregnancy. Commun Mental Health J. (2019) 55:1064-70. doi: 10.1007/s10597-019-00387-8

153. Organization WH. WHO Multi-Country Study on Women's Health and Domestic Violence against Women. Geneva: World Health Organization (2002).

154. Moghadam Z, Ardabily H, Salsali M, Ramezanzadeh F, Nedjat S. Physical and psychological violence against infertile women. J Fam Reprod Health. (2010) 4:65-7.

155. Jafarzadeh-Kenarsari F, Ghahiri A, Habibi M, Zargham-Boroujeni A Exploration of infertile couples' support requirements: a qualitative study. Int J Fertil Steril. (2015) 9:81. doi: 10.22074/ijfs.2015.4212

156. Ali EEK, El NAE-GA, Abdullah SO. Assessment of socio-demographic characteristics and self-esteem among infertile males. Malaysian J Nurs. (2019) 10:71-82. doi: 10.31674/mjn.2019.v10i04.010

157. Facchin F, Buggio L, Dridi D, Vercellini P. A woman's worth: the psychological impact of beliefs about motherhood, female identity, and infertility on childless women with endometriosis. J Health Psychol. (2019) 12:1359105319863093. doi: 10.1177/1359105319863093

158. Folkman S, Lazarus RS. An analysis of coping in a middle-aged community sample. J Health Soc Behav. (1980) 21:219-39. doi: 10.2307/2136617

159. Jafarzadeh F, Golzari M, Jomehri F, Poursamar SL, Sahraian K. The comparison of coping strategies with stress and marital satisfaction in women on the basis of infertility factor. Womens Health Bull. (2015) 2:1-4. doi: $10.17795 /$ whb-25227

160. Ammati R, Kakunje A, Karkal R, Kini G, Srinivasan J, Nafisa D. Stressful life events and quality of life in patients with somatoform disorders. Indian J Soc Psychiatry. (2019) 35:108. doi: 10.4103/ijsp.ijsp_24_18

161. Bokaie M, Simbar M, Ardekani SMY. Sexual behavior of infertile women: a qualitative study. Iran J Reprod Med. (2015) 13:645.

162. Jamali S, Zarei H, Jahromi AR. The relationship between body mass index and sexual function in infertile women: a cross-sectional survey. Iran J Reprod Med. (2014) 12:189.

Conflict of Interest: The authors declare that the research was conducted in the absence of any commercial or financial relationships that could be construed as a potential conflict of interest.

Copyright (c) 2020 Zarif Golbar Yazdi, Aghamohammadian Sharbaf, Kareshki and Amirian. This is an open-access article distributed under the terms of the Creative Commons Attribution License (CC BY). The use, distribution or reproduction in other forums is permitted, provided the original author(s) and the copyright owner(s) are credited and that the original publication in this journal is cited, in accordance with accepted academic practice. No use, distribution or reproduction is permitted which does not comply with these terms. 